\title{
O comportamento de consumo da mulher: um estudo sobre a compra de automóveis
}

Atualmente, face ao elevado poder de compra feminino, as mulheres são destaque no setor estratégico de marketing das empresas, inclusive no setor automotivo. Assim sendo, nesta pesquisa se objetivou analisar os atributos influenciadores no comportamento de consumo da mulher em relação à compra de carros, usando, para tanto, uma abordagem qualitativa e quantitativa. Na fase exploratória foram realizadas entrevistas em profundidade com três gerentes do setor automotivo aos efeitos de identificar, segundo suas visões, as características que influenciam a compra, bem como para validar o questionário a ser usado. Com tal instrumento de pesquisa fez-se o levantamento de dados, que deu como resultado cento e oitenta e sete (187) respostas válidas. Os três primeiros atributos mais considerados pelas mulheres na compra de carros novos, em ordem de importância, foram: a marca, seguido pela economia e preço. Na compra de carros usados foram, em primeiro lugar, a economia, seguido da marca e da segurança. As Anovas feitas entre as pontuações médias dadas aos dez atributos que constavam no instrumento considerando as variáveis sociodemográficas, resultaram em diferenças significativas em diversas condições. Dentre elas cabe destacar que as mulheres solteiras dão mais importância aos aspectos de segurança e à tecnologia. Outra conclusão importante foi que os itens femininos presente nos carros foram mais valorados pelas mulheres com ensino universitário incompleto, no entanto esse atributo contrariando a opinião dos gerentes entrevistados ocupa o último lugar entre os dez atributos disponibilizados no questionário.

Palavras-chave: Comportamento do Consumidor; Setor Automobilístico.

\section{The behavior of women's consumption: a study on the purchase of motor vehicles}

Currently, in view of the high female purchasing power, women are prominent in the strategic marketing sector of companies, including in the automotive sector Thus, the objective of this research was to analyze the influencing attributes in the consumption behavior of women in relation to the purchase of cars, using a qualitative and quantitative approach. In the exploratory phase, in-depth interviews were conducted with three managers of the automotive sector to identify, according to their visions, the characteristics that influence the purchase, as well as to validate the questionnaire to be used. With this instrument of research the data was collected, which resulted in one hundred and eighty-seven (187) valid answers. The first three attributes most considered by women in the purchase of new cars, in order of importance, were: the brand, followed by the economy and price. In the purchase of used cars were, first, the economy, followed by the brand and safety. The Anovas made between the average scores given to the ten attributes in the instrument, considering the sociodemographic variables, resulted in significant differences in several conditions. Among them, it should be noted that single women give more importance to security and technology aspects. Another important conclusion was that the female items present in cars were more valued by women with incomplete university education, however this attribute contrary to the opinion of the interviewed managers occupies the last place among the ten attributes made available in the questionnaire.

Keywords: Consumer Behavior; Automotive Industry.

Topic: Marketing e Estratégias Mercadológicas

Reviewed anonymously in the process of blind peer.
Received: 05/10/2017

Approved: 04/12/2017
Larissa Kepler Kummel

Universidade do Vale do Itajaí, Brasil

http://lattes.cnpq.br/8399799098098286

larissa@larissakummel.com.br

Miguel Angel Verdinelli

Universidade do Vale do Itajaí, Brasil

http://lattes.cnpq.br/5991426676776328

maverdinelli@gmail.com
Referencing this:

KUMMEL, L. K.; VERDINELLI, M. A.. O comportamento de consumo da mulher: um estudo sobre a compra de automóveis. Revista Brasileira de Administração Científica, v.8, n.3, p.13-26, 2017. DOI: http://doi.org/10.6008/SPC2179-684X.2017.003.0002 


\section{INTRODUÇÃO}

O comportamento de consumo desperta a atenção de pesquisadores em diversas temáticas, em especial da área de marketing; compreender a forma como se comporta o consumidor alvo e toma suas decisões instrumentaliza as empresas nas estratégias de marketing mais adequadas e eficazes (GROHMAN et al., 2012).

Atualmente, o mercado de consumo no Brasil abrange todas as classes sociais, independentemente de seu poder aquisitivo. Junto ao crescimento econômico dos últimos anos, tem surgido uma nova realidade: as mulheres, que além de exercerem uma grande influência na decisão de compra dos homens, consomem muito mais do que eles. Estas consumidoras ascenderam no mercado de trabalho e aumentaram seu poder aquisitivo (NAVES, 2010; LICHT et al., 2009). Tal fato se evidencia nas pesquisas recentes, cujos resultados são unânimes ao afirmarem que a mulher é a maior consumidora de produtos que existe. Ao contrário dos homens, elas gostam de comprar (BENTO, 2010).

Em face disto, o elevado poder de compra e de decisão feminina tem ganhado destaque na estratégia de marketing das empresas. Isto se verifica tanto no que diz respeito a produtos de consumo rotineiros, como por exemplo, os vendidos em supermercados e nas lojas de roupas ou souvenires, como também de bens duráveis, como automóveis e apartamentos (GOMES et al., 2011).

A produção de automóveis no Brasil encontra-se em 8ㅇ lugar no ranking mundial. Conforme apontam os dados oferecidos pelo Ministério de Desenvolvimento da Indústria e Comércio, a produção mundial de veículos em 2014 foi de 89,7 milhões de unidades, dos quais 31 milhões foram produzidos no Brasil. De igual sorte, os dados e estatísticas apontam que a indústria automobilística do Brasil possui uma grande significância no PIB (Produto Interno Bruto) do país, e apesar da instabilidade na economia nacional, gera um expressivo número de empregos diretos e indiretos.

A crise que assombra o país provoca uma queda significativa nas vendas de 5,69\% de veículos automotores no mês de novembro de 2013 para o mês de novembro de 2014. No entanto o licenciamento de automóveis atingiu o expressivo número de 2.224 .521 no ano de 2014. Tais resultados representam a relevância da indústria automobilística brasileira e sinalizam uma possibilidade de saturação do mercado e proliferação de consumidores, além de mais disputados, com maior nível de exigência (LEMOS, 2007).

Ainda é importante ressaltar que o brasileiro está gastando 2000 reais a mais no setor automobilístico, o que reduziu um pouco os impactos da crise econômica no setor de veículos do Brasil. A compra de um automóvel novo, muitas vezes, pode ser a realização de sonho, de um objetivo alcançado pelo consumidor (YAMAGUTI, 2005).

Pesquisas apontam que desde as classes com menor poder aquisitivo, quanto as que mais podem consumir, o automóvel é o maior desejo de compra do ser humano, superando inclusive o sonho da casa própria (CORDEIRO, 2010). Além do mais, para Gupta et al. (1995), conhecer quais são os atributos influenciadores na compra do veículo pode contribuir com o gerente, tanto na hora de redesenhar o produto, como na satisfação do consumidor. 
Assim, o tema revela lacunas conceituais no campo científico referente ao conhecimento da compra de automóveis realizada pelas mulheres. Grohman et al. (2012) destaca um número considerável de pesquisas internacionais sobre o comportamento do consumidor em relação aos automóveis, mas destacam uma carência de estudos nacionais sobre o tema, afirmam que não chegam a um consenso sobre os aspectos importantes na decisão da compra.

Naves (2012) também assinala uma carência de estudo nacional sobre comportamento de consumo em relação à compra de veículos pelas mulheres (NAVES, 2012). Além do mais, Silverstein e Sayre pela Harvard Business Review destacam que, apesar de as mulheres serem responsáveis por $60 \%$ da decisão de compras de veículos, as indústrias automobilísticas são exemplos de empresas que negligenciam o consumo feminino.

À base de dados do Esmerald, encontra-se cerca de 40 artigos referentes a compra feminina. A amostra desta base de dados está baseada, principalmente, na diferença de gêneros, e nas compras por impulso. $\mathrm{O}$ objeto de pesquisa está relacionado principalmente a moda, fitness, cosméticos, compras online. Além do mais, a escolha do bem, objeto deste estudo, deu-se em virtude das características do mercado automotivo que, apesar das constantes oscilações, conforme os dados apontados pelo Ministério de Desenvolvimento da Indústria e Comércio possui uma grande representação econômica no país, sendo responsável por cerca de 23\% do PIB industrial (MDIC/2014) e serve como termômetro para a economia nacional. Corazza (2013) menciona que a compra de carros faz parte da construção de um novo estilo de vida do consumidor e, ainda, associa-o a uma nova fase da civilização.

Ainda, com base na realidade descrita anteriormente, há pouca produção acadêmica referente a compra de automóveis pelas mulheres, além da crise econômica instaurada no setor, destaca-se a relevância problemática da pesquisa a ser tratado neste estudo sobre o comportamento de compra da mulher em relação a veículos automotores na categoria carros novos e usados. Desta maneira, justifica-se esse trabalho pelo subsídio que poderá trazer a respeito do tema, apresentando o aporte de dados empíricos que demonstram quais atributos influenciam no comportamento de consumo feminino.

A contribuição desta pesquisa pode ser tanto do ponto de vista acadêmico quanto prático, pois as empresas fabricantes ou comercializadoras de veículos, assim como os próprios vendedores podem dispor de informações que marquem as tendências dessas consumidoras. Com base no texto descrito anteriormente, a presente pesquisa visa a responder a seguinte pergunta de pesquisa: Quais são os principais atributos dos veículos que influenciam no comportamento de compra das mulheres com relação a carros novos?.

Com o propósito de dar resposta a tal questionamento, formulou-se o seguinte objetivo geral: Analisar os atributos influenciadores no comportamento de consumo da mulher em relação à compra de carros. A seguir desta introdução, é apresentado o marco teórico. Na seção seguinte, detalha-se como se obteve o material e os métodos utilizados, seguidos da descrição e análise dos dados. Por último, são feitas as considerações finais e disponibilizado o referencial bibliográfico citado no texto. 


\section{REVISÃO TEÓRICA}

\section{Definições sobre o comportamento do consumidor}

A teoria que fundamenta este trabalho encontra-se descrita neste capítulo e aborda o comportamento do consumidor, seus conceitos, características femininas e principalmente, os atributos dos carros motivadores de compra pelas mulheres. O comportamento do consumidor relaciona diversas teorias, objetos de estudos que procuram explicar e relacionar atitudes, intenções e ações dos consumidores em geral (GOUVEIA et al., 2012). É uma área de conhecimento que recebe contribuições de diversas ciências como: psicologia, economia entre outras (PILLI, 2012).

É uma ciência nova. Os primeiros livros foram publicados a partir de 1968. A maioria das universidades não fazia qualquer esforço antes de 1970 para reconhecer a relevância do universo de consumo, todavia o campo tem crescido significativamente nos últimos anos (JEDDI et al., 2013). O comportamento humano é complexo, suscitando controvérsias e contradições nas formas de defini-lo. 0 mesmo acontece com o comportamento do consumidor, tendo em vista que muitos profissionais consideram o segredo do sucesso do marketing. O consumo se manifesta em todas as sociedades e é um importante meio de autoexpressão identitária e delimitação social (GOMES et al., 2011).

Taylor (1974) entende que: "Compreender o papel do risco no comportamento do consumidor pode fornecer a base para a combinação de teoria do comportamento do consumidor com ação de gerenciamento de marketing". O principal objeto de estudo do comportamento de compra dos consumidores é entender profundamente o comportamento das pessoas, suas necessidades, seus desejos e suas motivações. Compreender o processo de como, quando e o porquê os consumidores compram, a seleção de produtos e a decisão de compra, o uso ou a disposição de produtos, ideias ou experiências para satisfazer as necessidades e desejos desses consumidores (SAMARA et al., 2005). Em outras palavras, estudar o comportamento do consumidor é entender como eles compram.

\section{Comportamento de consumidor feminino}

Dichtwald et al. (2011) se pronuncia: "[...] quando as mulheres têm mais dinheiro, usam-no diferentemente dos homens. Fazem escolhas diferentes. Investem, gastam e têm sentimentos de forma diferentes." O quadro 1 apresenta os resultados de diversas pesquisas realizadas nos principais bancos de dados nacionais e internacionais sobre o comportamento do consumo feminino, bem como, características femininas importantes a serem consideradas na hora da compra. A relevância deste mercado feminino, bem como, o seu potencial de consumo, deve ser considerado pelas empresas que desejam atender às necessidades de suas clientes (JATO et al., 2009).

Quadro 1: Pesquisas sobre o comportamento do consumidor feminino.

\begin{tabular}{|c|l|l|}
\hline Autor/Ano & \multicolumn{1}{|c|}{ Objetivo da pesquisa } & \multicolumn{1}{c|}{ Resultados } \\
\hline \multirow{3}{*}{ Ocke (2013). } & $\begin{array}{l}\text { Discutir o comportamento de consumo no que se } \\
\text { refere à influência dos membros da família no processo } \\
\text { de tomada de decisão de compra de viagens de férias." } \\
\text { "Desenvolveu-se um estudo exploratório onde foram } \\
\text { coletados 40 questionários entre os dias 15 de Junho e e }\end{array}$ & $\begin{array}{l}\text { decisão de compra foram identificadas na literatura, } \\
\text { porém, este estudo utilizou o modelo de três etapas do } \\
\text { processo de tomada de decisão: reconhecimento do } \\
\text { problema, busca por informação e decisão final de }\end{array}$ \\
\hline
\end{tabular}




\begin{tabular}{|c|l|l|}
\hline & $\begin{array}{l}15 \text { de Julho de } 2012 \text { de respondentes que haviam } \\
\text { comprado um ou mais pacotes de viagem nos últimos } \\
\text { dois anos em uma agência de turismo da cidade de São } \\
\text { Paulo. }\end{array}$ & $\begin{array}{l}\text { compra. Os resultados indicam que a influência de pais } \\
\text { e filhos no processo decisório varia de acordo com as } \\
\text { etapas do processo e que apesar de grande parte das } \\
\text { decisões sejam tomadas em conjunto, as mulheres } \\
\text { apresentam maior influência nos três estágios de } \\
\text { tomada de decisão, principalmente na etapa de busca } \\
\text { por informação. Neste cenário, o trabalho aponta para } \\
\text { a necessidade de uma maior diversidade de pesquisas } \\
\text { empíricas sobre o comportamento de consumo das } \\
\text { famílias em relação à aquisição de serviços turísticos." }\end{array}$ \\
\hline $\begin{array}{c}\text { Jossiasen et } \\
\text { al. (2010). }\end{array}$ & $\begin{array}{l}\text { O estudo objetivou avaliar as influências de gênero, } \\
\text { idade e situação demográfica no consumo }\end{array}$ & $\begin{array}{l}\text { Os resultados da pesquisa dos autores apontam que os } \\
\text { consumidores são fortemente influenciados pelas suas } \\
\text { características demográficas, principalmente com } \\
\text { relação ao gênero e a idade. }\end{array}$ \\
\hline $\begin{array}{c}\text { Klerk et al. } \\
\text { (2006). }\end{array}$ & $\begin{array}{l}\text { Estudo analisou o perfil feminino com relação a a design e o material do produto, especialmente cor e } \\
\text { compras na área da estética. }\end{array}$ & $\begin{array}{l}\text { O textura são aspectos importantes a serem considerados } \\
\text { pelas mulheres na área da estética. }\end{array}$ \\
\hline $\begin{array}{c}\text { Shifmann et } \\
\text { al. (1997). }\end{array}$ & $\begin{array}{l}\text { Shifmann et al. (1997) destaca que os profissionais de } \\
\text { marketing segmentaram o mercado feminino, } \\
\text { desenvolvendo categorias que diferenciam as as } \\
\text { motivações das mulheres, as quem trabalham e as que } \\
\text { não trabalham. }\end{array}$ & $\begin{array}{l}\text { Mulheres que não trabalham gastam mais tempo indo } \\
\text { as compras do que as que não trabalham. A tendência } \\
\text { é que as que trabalham sejam mais leais a marca e a } \\
\text { loja. }\end{array}$ \\
\hline
\end{tabular}

\section{Atributos dos produtos}

Grohman et al. (2012) destaca que "A forma mais clássica de conhecer o comportamento do consumidor é por meio da identificação dos atributos que podem interferir na decisão de compra dos mesmos". Peter et al. (1999) corroboram com esta visão, alegando que os atributos são os principais estímulos da compra. Ckinkota et al. (2009) destaca que os atributos são a forma pela qual as características dos produtos fornecem solução para os clientes. Conhecer os atributos que influenciam no julgamento do comprador é uma informação primordial que privilegia os administradores de marketing (URAN et al., 2001).

Para Gupta et al. (1995) o consumidor primeiramente analisa o produto e seus atributos. A seguir analisam a marca para a formação da sua preferência. As extensas buscas de informações sobre os atributos podem levar o consumidor a uma difícil decisão de compras. O conhecimento dos atributos importantes para um determinado grupo de consumidores é importante para promover esse produto e para desenvolver os veículos, pois desta forma eles provocaram uma maior satisfação ao consumidor (GUPTA et al., 1995).

Além do mais, para uma melhor compreensão do tema, de uma forma condensada, o quadro 2 apresenta a visão de autores internacionais acerca dos resultados de pesquisas sobre atributos relacionados à compra de automóveis. Já o quadro 6 traz resultados de diversas pesquisas internacionais sobre o mercado automobilístico. Inclusive, em alguns comentários, há os resultados de pesquisas que destacam o público feminino.

Quadro 2: Atributos decisivos na compra de automóveis - Artigos internacionais.

\begin{tabular}{|c|l|l|}
\hline Autores/Ano & \multicolumn{1}{|c|}{ Objetivo da pesquisa } & \multicolumn{1}{c|}{ Resultados } \\
\hline $\begin{array}{c}\text { Train et al. } \\
\text { (2007). }\end{array}$ & $\begin{array}{l}\text { O estudo examina a influência dos } \\
\text { atributos do veículo, a fidelidade à marca, } \\
\text { à linha de produtos, características e } \\
\text { concessionárias. }\end{array}$ & $\begin{array}{l}\text { Opinam que os consumidores optaram pelos fabricantes } \\
\text { americanos em virtude das alterações nos atributos básicos do } \\
\text { veículo, a saber: preço, tamanho, potência, custo operacional, tipo } \\
\text { de transmissão, confiabilidade e corpo digital. }\end{array}$ \\
\hline \multirow{3}{*}{ Wu (2011). } & $\begin{array}{l}\text { O objetivo da pesquisa foi analisar o } \\
\text { porquê muitos consumidores chineses, } \\
\text { americanos preferem marcas de } \\
\text { automóveis japonesas ou europeias do } \\
\text { que as marcas americanas }\end{array}$ & $\begin{array}{l}\text { Os americanos, chineses percebem a imagem do Japão mais } \\
\text { favoravelmente, os Estados Unidos, e a Europa no meio dos dois } \\
\text { países. A pesquisa ressalta que país/imagem é importante, mas é } \\
\text { menos do que outros atributos extrínsecos, como preço, marca e } \\
\text { serviço, e confiabilidade e segurança são os atributos intrínsecos }\end{array}$ \\
\hline
\end{tabular}




\begin{tabular}{|c|c|c|}
\hline & & $\begin{array}{l}\text { mais importantes. Opiniões de familiares e amigos são importantes, } \\
\text { segundo, o prévio conhecimento e informação a partir de relatórios } \\
\text { de consumo. Americanos chineses não são fiéis à marca. Um } \\
\text { confiável e seguro automóvel é o fator mais importante que afeta } \\
\text { suas decisões de compra. Suportes publicitários e vendedores têm } \\
\text { influência apenas marginal. Por isso, o conselho que o autor dá é } \\
\text { para reforçar ou melhorar a influência interpessoal. }\end{array}$ \\
\hline $\begin{array}{c}\text { Gupta et al. } \\
\text { (1995). }\end{array}$ & $\begin{array}{l}\text { O objetivo do estudo é analisar os } \\
\text { atributos influenciadores na compra de } \\
\text { automóveis pelos consumidores de } \\
\text { carros. }\end{array}$ & $\begin{array}{l}\text { Os consumidores se apoderam de um conjunto de atributos para } \\
\text { tomar as decisões. Por exemplo: o conforto, em vez de } \\
\text { comprimento e largura do carro pode ser suficiente para uma } \\
\text { decisão. O estudo identifica nove atributos determinantes na } \\
\text { influência do consumidor de carros. Sejam eles: } 1 \text {. Preço, } 2 . \\
\text { Confiabilidade; } 3 \text {. Economia; } 4 \text {. Espaço para as pernas; } 5 \text {. Motor; } 6 . \\
\text { Manutenção; 7. Esportivo; } 8 \text {. Bem estar dos bancos da frente; } 9 . \\
\text { Capacidade da bagagem; }\end{array}$ \\
\hline $\begin{array}{l}\text { Dardis et al. } \\
\text { (1994). }\end{array}$ & $\begin{array}{l}\text { A pesquisa investiga a relação de } \\
\text { atributos dos automóveis e } \\
\text { características domiciliares às } \\
\text { preferências dos consumidores para } \\
\text { carros japoneses. A análise foi confinada } \\
\text { às famílias que compraram carros novos } \\
\text { em } 1986 \text {. }\end{array}$ & $\begin{array}{l}\text { O estudo concluiu que as famílias, interessadas em carros de } \\
\text { consumo de combustível mais eficiente e mais pesados, bem como, } \\
\text { carros com taxas de depreciação mais baixas e menor frequência de } \\
\text { reparação, são mais propensas a comprar carros japoneses do que } \\
\text { os carros não-japoneses. As famílias tendem a comprar automóveis } \\
\text { japoneses por causa de questões de qualidade não porque eles são } \\
\text { pequenos. Esses achados influenciam na indústria automobilística } \\
\text { os EUA, que enfrenta o aumento da concorrência em uma } \\
\text { economia global. }\end{array}$ \\
\hline $\begin{array}{l}\text { Mannering et } \\
\text { al. (1991). }\end{array}$ & $\begin{array}{l}\text { O estudo analisa a importância da marca } \\
\text { como atributo preponderante para a } \\
\text { compra de automóveis. }\end{array}$ & Constatam que a marca não é tão importante para o consumidor \\
\hline
\end{tabular}

De igual forma, a presente pesquisa compilou alguns resultados de pesquisas nacionais acerca da compra de automóveis, atributos influenciadores e características do público feminino para a decisão da compra de automóvel, conforme se apresenta no quadro 3, autointitulado 'Pesquisas nacionais sobre o comportamento de consumo feminino na compra de automóveis'.

Quadro 3: Pesquisas nacionais sobre o comportamento de consumo feminino na compra de automóveis.

\begin{tabular}{|c|l|l|}
\hline Autor/Ano & \multicolumn{1}{|c|}{ Objetivo da pesquisa } & \multicolumn{1}{c|}{ Resultados } \\
\hline $\begin{array}{c}\text { Naves } \\
\text { (2012). }\end{array}$ & $\begin{array}{l}\text { A pesquisa objetiva estudar o } \\
\text { perfil feminino na compra de } \\
\text { automóveis. }\end{array}$ & $\begin{array}{l}\text { "As mulheres entrevistadas quando adquirem um automóvel novo: 'pensam em } \\
\text { praticidade, benefícios e vantagens que o bem Ihe dá de retorno, } \\
\text { principalmente na mínima preocupação com serviços de manutenção que os } \\
\text { automóveis novos garantem'. Ainda, nesta pesquisa, constatou-se uma } \\
\text { diferenciação comportamental com relação às diversas fases da compra. }\end{array}$ \\
\hline $\begin{array}{c}\text { Artoni et al. } \\
\text { (2010). }\end{array}$ & $\begin{array}{l}\text { comportudo analisa o devem ser levados em } \\
\text { consideração na compra de } \\
\text { automóveis. }\end{array}$ & $\begin{array}{l}\text { Foi possível destacar diferenças significativas no comportamento de compra } \\
\text { das mulheres que devem ser levadas em consideração nos esforços de } \\
\text { marketing. A pesquisa aponta ser uma preocupação mais significativa para as } \\
\text { mulheres os atributos como: argumentação do vendedor no ponto de venda, os } \\
\text { serviços pós-venda, cuidados com manutenção e seguro do veículo. O estudo } \\
\text { aponta também oportunidades de construção de diferenciais competitivos a } \\
\text { empresas no ramo automobilístico. }\end{array}$ \\
\hline Jato et al. & $\begin{array}{l}\text { A pesquisa estuda a diferença e } \\
\text { as semelhanças dos gêneros na } \\
\text { (2009). }\end{array}$ & $\begin{array}{l}\text { A pesquisa revela que existem mais semelhanças que diferenças na hora de } \\
\text { homem e mulher escolherem seu automóvel. Discorrem que: a semelhança } \\
\text { entre as escolhas sugere que as representações, os significados e valores } \\
\text { atribuídos ao automóvel por homens e por mulheres são similares e, desta } \\
\text { forma, a estratégia de diferenciação de produtos não se aplica à indústria } \\
\text { automobilística. }\end{array}$ \\
\hline
\end{tabular}

\section{METODOLOGIA}

O método utilizado na presente pesquisa tem caráter qualitativo e quantitativo e busca definir e processar a coleta, o tratamento e a análise dos dados, visando analisar os resultados da pesquisa. No intuito de facilitar o entendimento do método da pesquisa e o desenvolvimento das suas atividades, o quadro 4 explica o desenho da pesquisa. A presente pesquisa optou pela realização das entrevistas com profundidade, 
justamente para explorar o conhecimento e a experiência de profissionais que possuem uma considerável informação sobre o problema de pesquisa. Essa técnica costuma render excelentes informações e o resultado é bastante considerável (CHURCHILL JUNIOR et al., 2011).

Quadro 4: Roteiro da pesquisa.

\begin{tabular}{|l|}
\hline \multicolumn{1}{|c|}{ 10 FASE: EXPLORATÓRIA } \\
\hline Elaboração do roteiro para entrevistas. \\
\hline Aplicação das entrevistas com profundidade. \\
\hline Análise das entrevistas \\
\hline \\
\hline Elaboração do instrumento \\
\hline Realização do pré-teste \\
\hline Aplicação do instrumento (Questionário)-187 mulheres \\
\hline Análise dos dados \\
\hline Resultados, conclusões e limitações da pesquisa \\
\hline
\end{tabular}

O roteiro das entrevistas foram elaborados com base na bibliografia mencionada e os três gerentes foram escolhidos por conveniência, tendo em vista a disponibilidade deles. As entrevistas foram analisadas, buscando melhor compreensão do processo de compra de automóveis pelo público feminino, além dos atributos considerados e valorizados por este perfil.

Após a preparação, execução e conclusão da etapa exploratória, iniciou-se a elaboração do instrumento de pesquisa. Através das entrevistas em profundidade, e a revisão bibliográfica, foram identificados os principais atributos valorizados pelos entrevistados em relação ao processo de compra de automóvel pelas mulheres. Posteriormente, estes atributos foram utilizados para a elaboração do instrumento de coleta de dados.

Na presente pesquisa, contou-se com as respostas de 187 mulheres de uma pesquisa survey com um questionário de autopreenchimento na escala Likert de 1 a 5, que laboravam na cidade de Balneário Camboriú e Itajaí/SC. A amostra foi escolhida por conveniência e disponibilidade das entrevistadas. Posteriormente, organizou-se uma planilha eletrônica no Excel os dados levantados na pesquisa survey. Eles foram exportados para um software estatístico com a finalidade de analisar as relações que possam ser identificadas entre as avaliações.

\section{RESULTADOS E DISCUSSÃO}

Diversos itens ou atributos mencionados pelos entrevistados também foram encontrados nas pesquisas apontadas no referencial teórico. Gupta et al. (1995) pesquisa os mesmos atributos determinantes da compra de automóvel, sejam eles: tamanho do automóvel; preço, economia, potência do motor, design, segurança, confiabilidade.

Para esclarecer e objetivar mais a pesquisa foram acoplados os itens dos atributos em seus respectivos atributos. Assim, foram selecionados os seguintes atributos influenciadores na compra de carros pelas mulheres: preço, marca, design do veículo, segurança, conforto, tecnologia, mimos para mulheres, atendimento, velocidade e economia. $\mathrm{O}$ atributo design foi um dos mais considerados pelos gerentes de veículos novos. Com relação ao atributo design foi considerado os itens beleza, largura, comprimento, altura do carro e cor. Ainda, o entrevistado 2 destaca que o atributo design é considerado pelas mulheres solteiras, 
juntamente com outros, um dos mais importantes na hora de escolher seu automóvel. Diversos foram os comentários dos entrevistados acerca da importância desses itens para o público feminino.

[...] mas o feminino a gente nota que é mais importante o design, o motor pode ser uma porcaria, mas tem um design bonito [...]. Exatamente, então, a mulher se preocupa mais com design, é o ponto forte, tanto que a Honda hoje já veio com modelos mais futurísticos, já tinha no passado, perdeu um pouco agora voltou, o Civic está mais moderno, a Crv vem com led, mulher quer ver esses detalhes no carro (Entrevistado 1).

Hoje o mercado vê um crescimento para carros survivers, camionetes pequenas, compactas, muitas montadoras estão trazendo esses carros, quem liderava era a Ford com a Eco Sport, depois tem a Crossfox, Idea, Crv são carros altos e survivers, a maioria é a mulher que compra, mulher gosta de carro alto, quer ver a frente do carro. A Honda tem um lançamento de um carro totalmente novo, a Hiv, que é um carro totalmente voltado ao público feminino, não que vão explorar q é para o público feminino, senão ninguém compra, mas a intenção é essa, são carros de 75000 até 90000 , possivelmente é uma pessoa que tenha uma condição mais razoável que vai comprar um carro desse, é casada tem filhos, precisa de espaço, quer segurança e um carro alto. [...] a Idea é um carro que vende muito bem para mulheres, pois muitas vezes ela se sente segura em um carro maior, em um trânsito realmente agressivo, a Freemont também um carro q te traz esse sentimento (Entrevistado 2).

Se engana quem pensa que melhor anda somente com carro pequeno, há mulheres que querem ter um carro maior, que quer se impor no trânsito (Entrevistado 2).

Minha esposa, minha sogra, minha cunhada, a arquiteta tem tudo EcoSport, ou já tiveram e tão com outro carro, mas tem gente que está com a EcoSport, o carro alto mesmo que ele não tenha segurança, ele te traz uma certa segurança (Entrevistado 1).

Se é uma mulher solteira, ela quer, conectividade, q tenha acessibilidade de bluetooth, tecnologia, a mulher solteira sem filhos, quer o carro q seja a identidade dela, esse carro combina comigo, tem meu perfil, carro robusto, feminino, design legal, me identifico com ele, tem muito disso, o carro dela tem q ser o reflexo dela, isso $p$ os homens também, mas a mulher acho que é mais, sinceramente eu vejo que a mulher quer se identificar mais com o veículo, que o carro reflita a imagem dela. Entrevistadora: Por isso que o design é importante que é a parte externa? Entrevistado: Totalmente importante. $\mathrm{O} \mathrm{Hb} 20$ é um carro q vende muito para mulher, não é um carro que tem tantos atributos e segurança como os carros da fiat, inclusive gasta mais que o nosso, mas o carro é bonito, as mulheres optam pela estética, apela muito, para a mulher tem o visual e apela por isso.

Na pesquisa referente a produtos estéticos também se destacou a relevância do design e do material do produto, em especial sua cor e textura (KLERK et al., 2006). Através destas declarações pareceu considerável a importância deste atributo na hora que o público feminino escolhe o seu veículo. O número total de entrevistados foi de 187 mulheres que trabalham nas cidades de Balneário Camboriú e Itajaí, proprietários de automóveis. Da amostra selecionada 68,44\% (128) das mulheres residem na cidade de Balneário Camboriú, 24,06\% (45) residem na cidade de Itajaí, 3,20\% (6) residem em cidades próximas e 4,81\% (9) não responderam à pergunta. Na tabela 1, reporta-se o estado civil da amostra, destacando-se o número de mulheres casadas de $48,66 \%$. Com relação aos filhos e estado civil das entrevistadas constatou-se que 49,93\% da amostra possuem filhos, conforme se exibe na tabela 2.

Em relação à idade das entrevistadas, Jossiasen et al. (2010) também menciona a idade como uma das características demográficas mais importantes a serem avaliadas na hora de estimular a compra de um consumidor por um determinado produto. A tabela 3 apresenta a frequência e o percentual em relação à idade das entrevistadas, condizentes à geração delas. As gerações estudadas são as mulheres das gerações y, x e baby bommers. 
O nível de escolaridade pode ser observado na tabela 4, em que se destaca o nível superior com 36,55\% (68) e o nível com pós-graduação com $41,17 \%$ (77). Os dois juntos totalizam $77,72 \%$ (56) dos entrevistados. Já a tabela 5 apresenta as faixas de renda familiar dos entrevistados. Com renda acima de R\$ $7.880,00 /$ mês, somam 44,91\% (48) dos entrevistados que responderam esta questão.

Tabela 1: Estado civil da amostra.

\begin{tabular}{|c|r|r|}
\hline Estado civil & $\mathbf{N}^{\circ}$ de entrevistadas & \multicolumn{1}{|c|}{ Percentual } \\
\hline Solteiras & 62 & $33,15 \%$ \\
\hline Casadas & 91 & $48,66 \%$ \\
\hline Divorciadas & 9 & $4,81 \%$ \\
\hline Separadas & 14 & $7,48 \%$ \\
\hline Viúvas & 3 & $1,60 \%$ \\
\hline Uniões estáveis & 4 & $2,13 \%$ \\
\hline Outros & 3 & $1,60 \%$ \\
\hline Sem respostas & 1 & \\
\hline
\end{tabular}

Tabela 2: Filhos e estado civil.

\begin{tabular}{|c|c|c|}
\hline Possui filhos & Casadas & Solteiras \\
\hline $49,93 \%(93)$ & $33,15 \%(62)$ & $4.81 \%(9)$ \\
\hline
\end{tabular}

Tabela 3: Idade das participantes.

\begin{tabular}{|l|r|r|}
\hline \multicolumn{1}{|c|}{ Geração e idade } & $\mathbf{N}^{\circ}$ de entrevistados & \multicolumn{1}{|c|}{ Percentual } \\
\hline Geração y (18 aos 35 anos) & 82 & $43,87 \%$ \\
\hline Geração x (36 aos 50 anos) & 69 & $36,98 \%$ \\
\hline Geração baby boomers (50 aos 64 anos) & 26 & $13,90 \%$ \\
\hline Sem respostas & 10 & $5,34 \%$ \\
\hline
\end{tabular}

Tabela 4: Nível de escolaridade.

\begin{tabular}{|l|r|r|}
\hline \multicolumn{1}{|c|}{ Escolaridade } & $\mathbf{N}^{\circ}$ de entrevistados & \multicolumn{1}{c|}{ Percentual } \\
\hline Ensino Fundamental & & 1 \\
\hline Ensino médio incompleto & 0 & 0.53 \\
\hline Ensino médio completo & 17 & $0 \%$ \\
\hline Ensino superior incompleto & 23 & 9.09 \\
\hline Ensino superior completo & 68 & $12.23 \%$ \\
\hline Pós-graduação & 77 & $36.55 \%$ \\
\hline Vazia & 1 & $41.17 \%$ \\
\hline
\end{tabular}

Tabela 5: Faixa de renda.

\begin{tabular}{|l|r|r|}
\hline \multicolumn{1}{|c|}{ Faixas de Renda } & $\mathbf{N}^{\circ}$ de entrevistados & \multicolumn{1}{|c|}{ Percentual } \\
\hline$R \$ 15.760$ ou mais & 20 & $10.69 \%$ \\
\hline De $R \$ 7.880,00$ a $R \$ 15.759,99$ & 64 & $34.22 \%$ \\
\hline De $R \$ 3.152,00$ a $R \$ 7.879,99$ & 82 & $43.85 \%$ \\
\hline De $R \$ 1.576,00$ a $R \$ 3.151,99$ & 16 & $8.55 \%$ \\
\hline Até $R \$ 1.575,99$ & 3 & $1.60 \%$ \\
\hline
\end{tabular}

Considerando a escala Likert os atributos estudados no total da amostra colhida, possuíram as seguintes médias em ordem decrescente, com destaque ao atributo marca, que atingiu a média mais alta de 4.49 pelas mulheres. Visualiza-se isso na tabela 6 , a qual traz no seu bojo titular a 'média dos atributos' de 10 seções.

Tabela 6: Médias dos atributos.

\begin{tabular}{|l|c|c|}
\hline \multicolumn{1}{|c|}{ Atributos } & Média & Desvio Padrão \\
\hline Marca & 4.49 & 0.87 \\
\hline Economia & 4.34 & 0.55 \\
\hline Preço & 4.17 & 0.83 \\
\hline Segurança & 4.14 & 0.61 \\
\hline Conforto & 3.99 & 0.70 \\
\hline
\end{tabular}




\begin{tabular}{|l|l|l|}
\hline Velocidade & 3.93 & 0.94 \\
\hline Atendimento & 3.69 & 1.04 \\
\hline Design do veículo & 3.64 & 0.82 \\
\hline Tecnologia & 3.50 & 1.03 \\
\hline Itens femininos & 2.83 & 1.37 \\
\hline
\end{tabular}

O público da amostra desta pesquisa eram mulheres que trabalham. E conforme já foi apontado por Shifmann et al. (1997), a tendência é que as que trabalham sejam mais leais à marca e à loja do que as que não trabalham. A visão dos autores pode ser confirmada nesta pesquisa, pois o atributo marca atingiu a média mais alta pela amostra colhida. Logo, foi contrária a visão de Lemos (2007), que destaca a relevância da marca, mas não como o mais importante item a ser considerado pelos compradores de carros de luxo.

Com relação ao atributo economia, baseada na pesquisa de Pires et al. (2000), foram relacionados os itens, consumo de combustível e custo de manutenção. Os resultados da pesquisa vão ao encontro a visão de Pires et al. (2000) de que o atributo economia é bastante considerado pelos consumidores na escolha do automóvel. Sendo que nesta ocasião, foi o segundo atributo, com a média mais alta, considerado pelas mulheres da amostra.

Também vai de encontro com o resultado da pesquisa a visão de Naves (2012), que destaca a praticidade que a mulher deseja na hora de escolher seu veículo, com um menor serviço e custos de manutenção. Visão também adotada por Artonietti (2010). Assim, não se tem dúvidas da importância do atributo na escolha do automóvel. Como visto, a avaliação dos atributos pode mudar de acordo com o perfil da entrevistada. Neste subcapítulo, analisou-se com o teste de significância da Anova as seguintes variáveis sociodemográficas da amostra coletada: estado civil, gerações de idade, se possuíam filhos ou não, escolaridade e faixa de renda.

Com relação às variáveis solteira, casada e divorciada, como se exibe na Figura 1, na comparação simultânea se verificaram diferenças significativas $[F(2,173)=5,2890, p=0,00590]$. Portanto, fez-se a seguir o teste de Scheffé, pelo qual se constatou que as solteiras pontuam mais os aspectos tecnológicos, ou seja, dão mais importância do que as casadas.

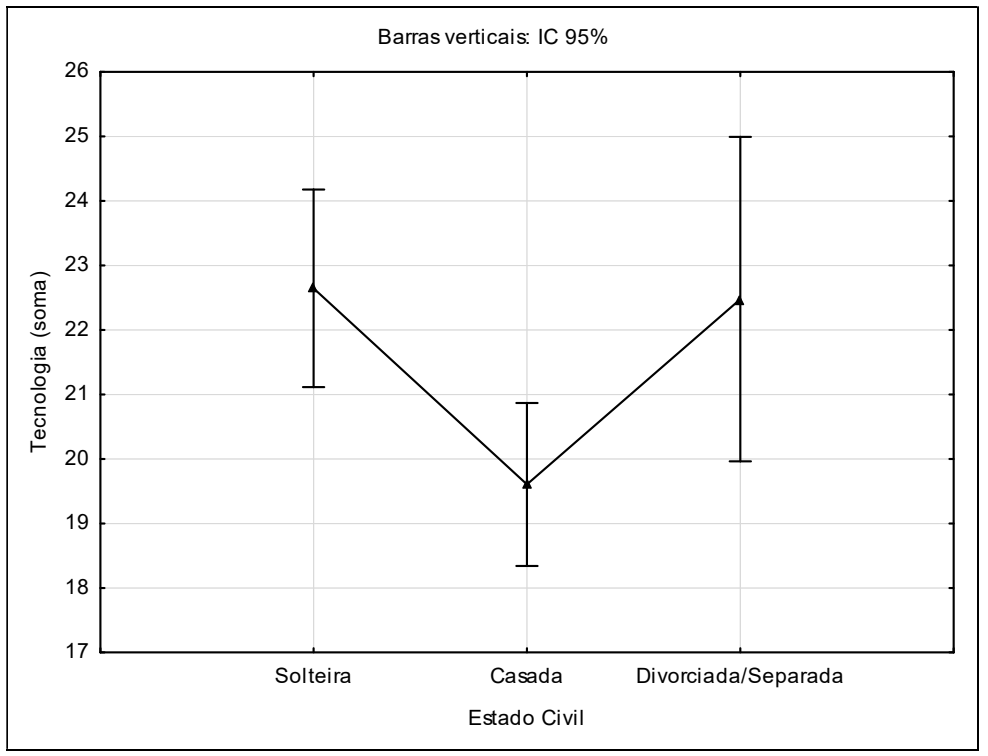

Figura 1: Anova: tecnologia $\mathrm{x}$ solteiras e casadas. 
Ainda na comparação simultânea de compradoras de carros solteiras e casadas se verificam diferenças significativas no relativo aos itens de segurança $[F(1,151)=4,1469, p=0,04346]$, como se mostra na figura 2. Foi utilizado o mesmo parâmetro semântico de análise, mas nesse caso, foi proposto um atributo específico.

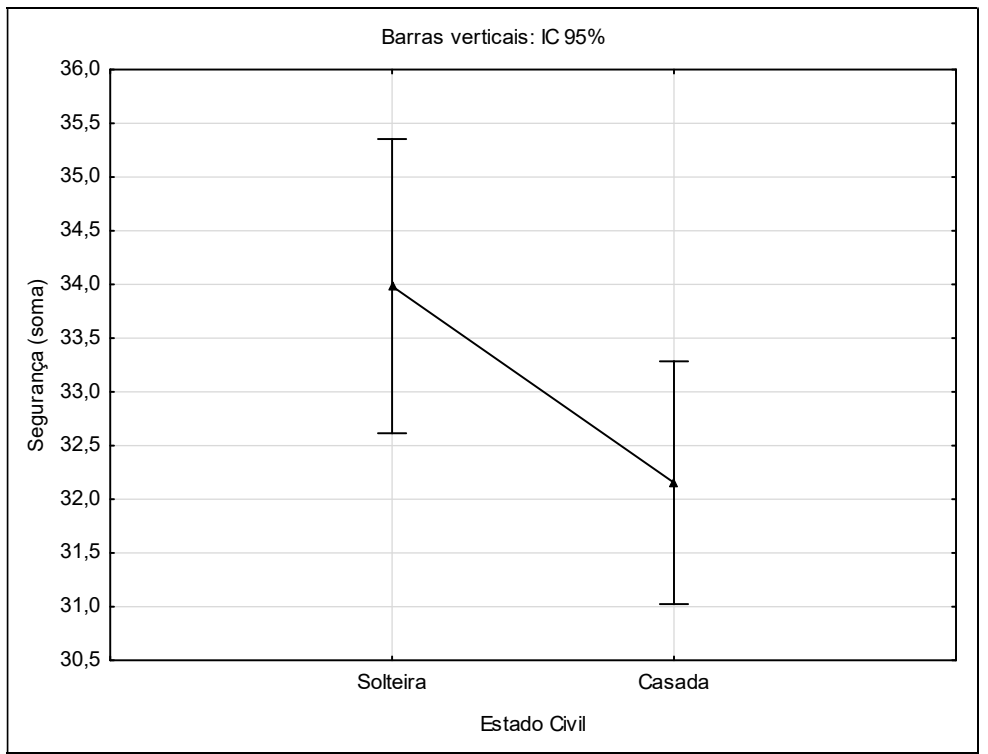

Figura 2: Anova solteiras e casadas x Atributo segurança.

Os resultados do teste de significância da ANOVA vão ao encontro com o referencial teórico apontado na presente pesquisa. Neste caso, a segurança e a tecnologia são dois atributos avaliados de forma significativamente diferentes por mulheres solteiras e casadas. Wells et al. (1996) também que o ser humano tem padrões de compras diferentes, e que pode estar relacionado ao seu estado civil. Na comparação simultânea de compradoras de carros que têm filhos com as que não têm verificam-se diferenças significativas $[F(1,185)=7,3926, p=0,00717]$, como exposto na figura 3 . Constatou-se que as que não têm filhos pontuam mais os aspectos tecnológicos, ou seja, dão mais importância.

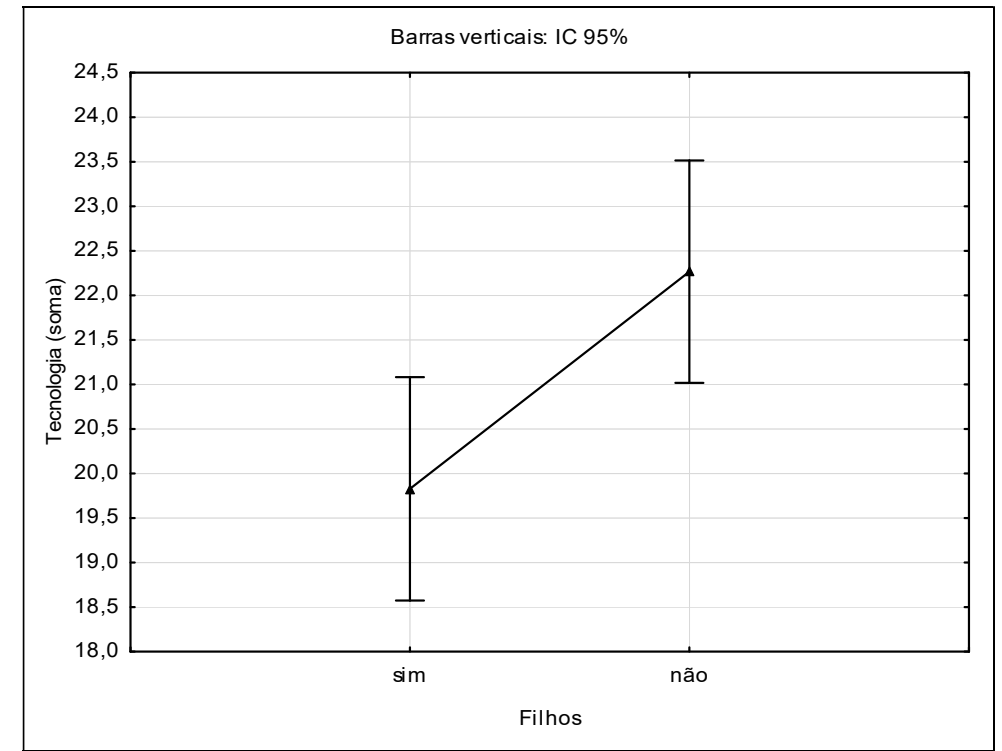

Figura 3: Anova: mulheres com filhos e sem filhos $x$ tecnologia.

O fato de as mulheres terem filhos ou não terem filhos vão ao encontro do referencial teórico apontado na presente pesquisa. Wells et al. (1996) também afirma que os padrões de compra do ser humano 
pode estar relacionado ao fato de terem filhos, sua idade, dependência ou não terem filhos. Em relação aos dados levantados na escolaridade, apresentado na Figura 4, ao considerar os itens femininos houve diferença na comparação simultânea $[F(3,180)=3,1265, p=0,02713]$ e na comparação pareada pelo teste de Scheffé as compradoras que têm ensino superior incompleto deram uma pontuação média significativamente maior do que as que têm ensino médio completo. Este resultado da ANOVA vai ao encontro da posição de Jossiasen et al. (2010), que afirma que a consumidora é bastante influenciada por suas características demográficas.

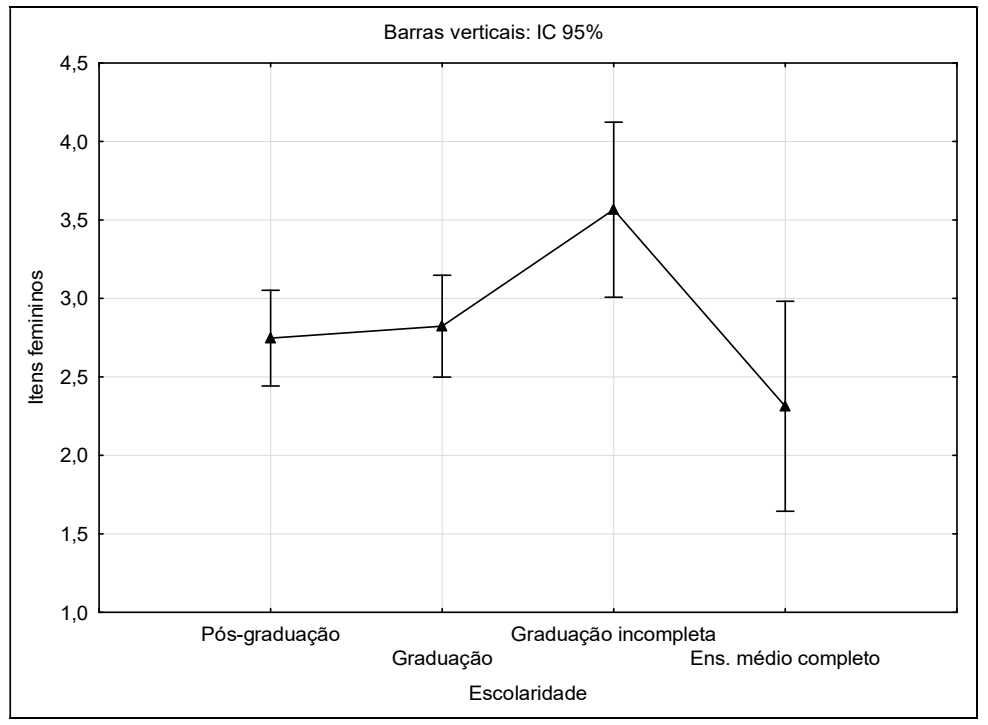

Figura 4: Tabela itens femininos $x$ escolaridade

\section{CONSIDERAÇÕES FINAIS}

O objetivo desta pesquisa está relacionado à identificação dos atributos dos automóveis novos e usados, os quais influenciam na compra da consumidora. Na revisão teórica foram encontrados inúmeros atributos influenciadores na compra de automóvel. A pesquisa exploratória definiu 10 principais atributos e 39 itens acoplados nestes atributos. A pesquisa survey apresentou a seguinte ordem decrescente do grau de importância, considerado pelas consumidoras: marca, economia, preço, segurança, conforto, velocidade, atendimento, design do veículo, tecnologia e itens femininos.

Chamou a atenção, nesta pesquisa, a relevância do atributo marca, considerado pelas mulheres como o mais importante. Seguido dos atributos economia e preço. Ambos os atributos possuem respaldo da sua relevância na fundamentação teórica e na etapa exploratória desta pesquisa. Assim, é considerado o item dos atributos mais importante pelas mulheres. O resultado corrobora a visão de Grohman et al. (2012), que o considera um dos principais atributos nos resultados da sua pesquisa.

Destaca-se também a avaliação feita do atributo design pelos entrevistados. Inúmeras foram as considerações que as mulheres se importavam muito com o design e beleza do veículo. Também com sua altura e largura. Esse atributo não foi considerado tão importante pelas mulheres, ficando em oitavo lugar. Em relação às médias pontuadas, somente o item beleza teve uma média superior a 4 . Sendo que os demais itens, largura, altura, comprimento e cor do automóvel tiveram uma média inferior a 4. A informação pode ser relevante para o setor automotivo e suas estratégias de marketing que visualizam a mulher como uma consumidora atrelada ao design do veículo, ou seja, são percepções, muitas vezes, superficiais e até mesmo 
erradas em relação à realidade, pois neste estudo, o item está em oitavo lugar, tendo sido outros atributos considerados muito mais importantes na hora da compra do automóvel pela amostra definida.

Uma limitação da amostragem por conveniência na pesquisa descritiva acontece pelo viés de seleção, podendo compreender amostras não representativas. No entanto, optou-se por esse tipo de amostragem em razão de envolver menos gastos financeiros, menos tempo e ser mais adequada ao propósito do estudo. De todos os modos e apesar de ter justificado o tipo de amostra escolhida, o fato gera uma limitação neste trabalho. Outra opção seria a avaliação do objetivo desta pesquisa através de um método somente exploratório, com a realização de uma pesquisa com grupos focais, com as próprias mulheres, proprietárias de seus automóveis, e também com os vendedores e gerentes de concessionárias para, posteriormente, confrontar os dados encontrados com os deste estudo.

\section{REFERÊNCIAS}

ARTONI, P. R. C. D.; BRAGA, R. P. F.; GARCIA, E. C.; SOFIATO, D.. Análises influenciam a compra de automóveis por mulheres. In: SEMINÁRIOS EM ADMINISTRAÇÃO, 13. Anais. Recife: 2010.

BENTO, C. A. R.. Don't Think Pink: comunicar o feminino. Dissertação (Mestrado em Marketing) - Universidade de Coimbra, Coimbra, 2010.

CHOO, S.; MOKHTARIAN, P. L.. What type of vehicle do people drive? The role of attitude and lifestyle in influencing vehicle type choice?. Transportation Research, v.38, p.201222, 2004

CHURCHILL JUNIOR, G. A.; BROWN T. J.; SUTER, T. A.. Pesquisa Básica de Marketing. São Paulo: Cengage Learning, 2011.

CORAZZA, R. I.. Criatividade, inovação e economia da cultura: abordagens multidisciplinares e ferramentas analíticas. Revista Brasileira de Inovação, v.12, n.1, p.207231, 2013

CORDEIRO, C. M. C.. A influência de jovens no processo de decisão de compra de automóveis. Dissertação (Mestrado) Faculdade de Ciências Empresariais, Belo Horizonte, 2010.

DARDIS, R.; FERRER, S. H.. Consumer Preferences for Japanese Automobiles. The Journal of Consumer Affairs, v.28, n.1, 1994

DYCHTWALD, M.; LARSON C.. Poder econômico das mulheres: entenda como a independência feminina pode influenciar o mundo positivamente. Rio de Janeiro: Elsevier, 2011

GOMES, N. M.; RIBEIRO B. L.; TRAVASSOS, J. V.. Poderosas consumidoras: um comparativo de consumo entre as jovens da baixada fluminense e da zona sul. Simpósio de Excelência em Gestão e Tecnologia. Anais. Resende: AEDB, 2011.

GROHMANN, M. Z.; BATTISTELLA, L. F.; SHOEDLER, A. R. Atributos importantes para o consumidor de automóveis: classificação em função experimental ou expressiva. FACES Journal, Belo Horizonte, v.11, n.1, p.67-86, 2012.
GUPTA, P. L.; LORD, K. L.. Identification of determinant attributes of automobiles: objective analogues of perceptual constructs. The Journal of Marketing Management, Spring, 1995.

JATO, R.; LICHT R. H. G.. Escolhas associadas ao automóve por homens e por mulheres: confluência ou divergência?. Gestão e Negócios, v.11, n.30, p.53-64, 2009.

JEDDI, S.; ATEAFI, Z.; JALALI, M.; POUREISA, A.; HAGHI, H.. Consumer behavior and consumer buying decision process. International Journal of Business and Behavioral Sciences, v.3, n.5, 2013.

JOSSIASEN, A.; ASSAF, A. G.; KARPEN, I.. Consumer ethnocentrism and willingness to buy: analysing the roles of the three demographic consumers caractheristics. International Marketing Review, v.28, n.6, 2011.

KLERK, H. M.; LUBBE, S.. Female Consumers evaluation of apparel quality: exploring the importance of aesthetics. Journal of Fashion Marketing and Management, v.12, n.1, 2006.

LEMOS, R. F.. Avaliação de atributos de compra no processo de aquisição de automóveis de alto valor. Dissertação (Mestrado em Administração de Empresas) - Pontifícia Universidade Católica do Rio Grande do Sul, Porto Alegre, 2007.

LYNCH, J. J.; SRULL, T. K.. Memory and attentional factors in consumer choice: concepts and research methods. Journal of Consumer Research, v.9, 1982.

MANNERING, F.; WINSTON, C.; CLIFFORD, Z.; SCHMALENSEE, R.. Brand Loyalty and the Decline of American Automobile Firms; Comments and Discussions. Brookings Papers on Economic Activity, p.67-114, 1991.

NAVES, F. V. R. N.. A mulher e a decisão de compra de automóvel: propósitos e processos. Dissertação (Mestrado em Administração de Empresas) - Faculdades Integradas de Pedro Leopoldo, Pedro Leopoldo, 2012.

OCKE, M. A. O.. Processo de decisão de compra de viagem de férias da família. Turismo em Análise, v.24, n.3, 2013. 
PILLE, L. E.. Julgamentos e decisão: limites para a racionalidade do consumidor. Dissertação (Mestrado em Administração) - Universidade de São Paulo, São Paulo, 2012.

PIRES, V. C.; MARCHETTI, R. Z.. Fatores influenciadores na escolha da fonte de informação na compra de automóveis novos: a importância da comunicação boca a boca. Encontro Nacional da Associação Nacional de Pós-Graduação e Pesquisa em Administração. Anais. Maringá: ANPAD, 2000.

SAMARA, B. S.; MORSCH, M. A.. Comportamento do consumidor: conceitos e casos. São Paulo: Pearson Prentice Hall, 2005.

SCHIFFMAN, L. G.; KANUK, L. L.. Consumer behavior. 6 ed. New Jersey: Prentice Hall, 1997.

TAYLOR, J. W.. The role of risk in consumer behavior. Journal of Marketing, v.38, n.2, p.54-60, 1974.
TRAIN K. E.; WINSTON, C.. Vehicle choice behavior and the declining market share. International Economic Review, v. 48, n. 4,2007

URDAN, F. T.; URDAN, A. T.. O impacto da marca sobre as preferências do consumidor: um experimento com cervejas. Encontro Nacional da Associação Nacional de Pós-Graduação e Pesquisa em Administração. Anais. Maringá: ANPAD, 2001.

WELLS, W. D.; GUBBAR, G.. Life cycle concept in marketing research. Journal of Marketing Research, v.3, p.4, 1996.

WU, G.. Country image, informational influence, collectivism/individualism, and brand loyalty: exploring the automobile purchase patterns of Chinese Americans. Journal of Consumer Marketing, v.28, n.3, p.169-177, 2011.

YAMAGUTI, C.. O comportamento do consumidor e a influência da família no processo de decisão de compra de automóveis novos. Dissertação (Mestrado e em Administração de Empresas) - Pontifícia Universidade Católica, São Paulo, 2005. 